\title{
Bazı Ruta L. Ekstraktlarının Biyoaktif Madde İçerikleri ve Radikal Kovucu Aktiviteleri
}

\author{
Cennet YAMAN $1^{\circ}$ (D) Deniz ULUKUŞ2(iD), Osman TUGAY3 \\ ${ }^{1}$ Bozok Ünv., Ziraat Fakültesi, Tarla Bitkileri Bölümü Yozgat, ${ }^{2}$ Selçuk Ünv., Fen Fakültesi, Biyoteknoloji Bölümü, Konya ${ }^{3}$ Selçuk Ünv., \\ Eczacılık Fakültesi, Farmasötik Botanik Anabilim Dalı, Konya \\ ${ }^{1}$ https://orcid.org/0000-0002-2364-8171, ${ }^{2}$ https://orcid.org/0000-0002-9627-5492, ${ }^{3}$ https://orcid.org/0000-0003-3980-7648 \\ $\bowtie:$ cennet.yaman@bozok.edu.tr
}

\section{ÖZET}

Ruta L. geleneksel tıbbi bitki olarak yaygin kullanılan, Rutaceae familyasının cinslerinden biridir. Bu çalışmada, yabani Ruta chalepensis L. (toprak üstü kısmı) ve Ruta montana L. (yaprak-çiçek ve gövde kısımları) türlerinin metanol ve etanol ekstraktlarının antioksidan aktiviteleri incelenmiştir. En yüksek ekstraktsiyon verimini $R$. montana (çiçek-yaprak) metanol ekstraktı sağlamıştır (\% $15.11,151.12 \pm 0.78 \mathrm{mg} / \mathrm{g}$ ). En düşük verim ise $R$. montana (gövde) etanol ekstraktında (\% 2.67, $26.66 \pm 0.50 \mathrm{mg} / \mathrm{g}$ ) tespit edilmiştir. $R$. chalepensis metanol ve etanol ekstraktlarının kuru madde içerisindeki toplam flavonoid madde içeriğinin, $R$. montana metanol çiçek-yaprak ekstraktı hariç diğer ekstraktlarından daha yüksek olduğu gözlenmiştir. Toplam flavonoid ve fenolik madde içeriği en az $R$. montana gövde kısmının etanol ekstraktlarından elde edilmiştir. Ayrica ekstraktların 2,2-diphenyl-1-picryl-hydrazyl-hydrate (DPPH) ve 2, 2'-Azino-Bis-3-Ethylbenzothiazoline-6-Sulfonic acid (ABTS) gibi radikal süpürücü aktiviteleri araştırılmış ve çözücü bazında değerlendirildiğinde $R$. chalepensis ekstraktlarının daha yüksek aktivite sergilediği gözlenmiştir. Sonuç olarak, bu çalışmada elde edilen verilerden yararlanılarak Ruta ekstraktlarının doğal bir antioksidan kaynağı olabilirliliğ̣i tartışılmıştır.

\section{Total Bioactive Contents and Radical Scavenging Activities of Some Ruta L. Extracts}

\section{ABSTRACT}

Ruta $L$. is a genus of the Rutaceae family, mostly used as a traditional medicinal plant. In this study, the antioxidant activities of methanolic and ethanolic extracts of wild Ruta chalepensis L. (above ground plant) and Ruta montana L. (leaves-flowers, stems) were assessed. The results showed that methanol extract of flower-leave of Ruta montana provided the highest yield of extraction $(15.11 \%$, $151.12 \pm 0.78 \mathrm{mg} / \mathrm{g}$ ) whereas the lowest yield was obtained in ethanol extract of stems of Ruta montana $(2.67 \%, 26.66 \pm 0.50 \mathrm{mg} / \mathrm{g})$. Total flavonoid content in dry weight of methanol and ethanol extracts of Ruta chalepensis was found higher than other extracts except methanol leaves-flowers extract of Ruta montana. It was determinated that ethanol extracts of Ruta montana stem sustained less total flavonoid and phenolic content. Also, radical scavenging activities such as 2,2-diphenyl-1-picryl-hydrazyl-hydrate (DPPH) and 2, 2'-Azino-Bis-3-Ethylbenzothiazoline-6-Sulfonic acid (ABTS) of extracts was investigated, and according to the solvent, it was revealed that extracts of Ruta chalepensis exhibited high activity. As a result, it has been discussed that Ruta can be used as a natural antioxidant by taking advantage of these data.

\section{Araştırma Makalesi}

$\begin{array}{ll}\text { Makale Tarihçesi } \\ \text { Geliş Tarihi } & : 21.11 .2018 \\ \text { Kabul Tarihi } & : 02.01 .2019\end{array}$

\section{Anahtar Kelimeler}

Ruta L.

Flavonoid

Fenolik

DPPH

ABTS

To Cite : Yaman C, Ulukuş D, Tugay O 2019. Bazı Ruta L. Ekstraktlarının Biyoaktif Madde İçerikleri ve Radikal Kovucu Aktiviteleri. KSÜ Tarım ve Doğa Derg 22(2): 193-201. DOI: 10.18016/ksutarimdoga.vi.486352

\section{GİRIŞ}

Kapalı tohumlu bitkiler arasında olan Rutaceae familyası 4 alt familya, 154 cins ve yaklaşık 2.100

\section{Research Article}

$\begin{array}{ll}\text { Article History } & \\ \text { Received } & : 21.11 .2018 \\ \text { Accepted } & : 02.01 .2019\end{array}$

Keywords
Ruta L.
Flavonoids
Phenolics
DPPH
ABTS

türden oluşmaktadır (Kubitzki, 2011; Morton ve Telmer, 2014). Dağılış olarak özellikle Avustralya ve Güney Afrika'da büyük çeşitlilik merkezine sahip olan, 
tropikal ve ılıman bölgelerde yayılış gösteren bir familyadır. Rutaceae familyası Türkiye Bitkileri Listesi'ne göre Citrus L., Dictamnus L., Haplophyllum A. Juss. Ve Ruta L. cinsleri olmak üzere 4 cins ile temsil edilmektedir. Citrus cinsi 9; Dictamnus cinsi 1; Haplophyllum cinsi 18; ve Ruta cinsi ise 6 taksonla temsil edilmektedir (Tugay, 2012, Tugay ve Ulukuş, 2017). Ruta cinsi tüm Dünya üzerinde 9 türle temsil edilmekte olup, 4 tür Akdeniz fitocoğrafik bölgesinde, 2 tür Korsika, 3 türde Kanarya Adaları'nda yayılış göstermektedir ve \% 55’i endemiktir (Salvo, 2008). Ruta cinsi ülkemizde $R$. chalepensis ve $R$. montana olmak üzere 2 türle temsil edilmektedir (Townsend, 1967). Ruta chalepensis, Akdeniz bölgesinin çok yıllık çalımsı bir bitkisidir, ancak dünyanın birçok bölgesinde llıman ve tropikal ülkelerde yaygın olarak yetişmektedir (Gonzalez-Trujano ve ark., 2006).

Önceki çalışmalar Ruta chalepensis türünün toprak üstü kısımlarının alkoloid, flavonoid, kumarin, uçucu yağ, saponin ve yağ asitleri gibi önemli biyoaktif bileşenler içerdiği tespit edilmiştir (Günaydin ve Göycıncık, 2005). Ruta chalepensis ekstraktlarının fitokimyasal bileşimi ile ilgili olarak, yaprak ve genç gövdenin alkaloidler, favonoidler, fenoller, amino asitler, furokumarinler, tanen, uçucu yă̆, glikozit, sterol, triterpen ve saponinler içerdiği bildirilmiştir (Aguilar-Santamaria ve Tortoriello, 1995; El Guiche ve ark., 2015).

$\mathrm{Bu}$ cinsin üyeleri birçok ülkede eski çağlardan günümüze kadar geleneksel tıpta geniş bir uygulama alanına sahiptir (Pollio ve ark., 2008). Örneğin abortif tedavide, antiromatizmal, hipoglisemik, antihelmintik, antipiretik, antiepileptik olarak, diyabet, epilepsi, vertigo, baş ağrısı ve göz hastalıklarının tedavisinde, bağırsak solucanlarının yok edilmesinde ve zehirlenmelerde kullanıldığı bilinmektedir. (Perry, 1980; Di Stasi ve ark., 1994; Bejar ve ark., 1997). İki türün ( $R$. montana ve $R$. chalepensis) infüzyon/dekoksiyon yöntemleri ile elde edilen örnekleri halk tıbbında yaygın olarak tonik ve ateş düşürücü olarak kullanılmaktadır. Ayrıca sıtma, antipiretik, analgesik, anti depresant, antidiyabetik, enflamatuar hastalıkların tedavisinde, antioksidan ve antimikrobiyal kaynağı olarak ta kullanılmaktadır (Iauk ve ark., 2004; Khlifi ve ark., 2013; Kacem ve ark., 2014; Loizzo ve ark., 2018).

Ruta montana Kuzey Doğu Cezayir'de halk tarafindan geleneksel olarak adet söktürücü, eskarotik, antispazmodik olarak kullanılmaktadır (Zellagui ve ark., 2012). Ayrıca İspanya'da, ateş düşürücü, antispazmodik ve bağırsak solucanlarına karşı bir terapi olarak kullanılmıştır (Forment and Roquest, 1941). Ruta chalepensis romatizma, ateş, havale ve bazı sinir hastalıklarının tedavisinde Çin, Hindistan, Afrika ve Suudi Arabistan ülkelerinin geleneksel tıbbında aktif olarak kullanılmaktadır (Al-Said ve ark., 1990; Mansour ve ark., 1990; Iauk ve ark., 2004).
Bazı ham ekstraktlarında anti-fertilite aktivitesi olduğu, Türk ve Çin kültürlerinde anti-fertilite ajanı olarak kullanıldığı bilinmektedir (Ulubelen ve ark. 1994). Akdeniz bölgesinde, Cezayir, Kıbrıs ve İsrail gibi bazı ülkelerde, $R$. chalepensis yaprak infüzyonları, ruhsal rahatsızlıkların tedavisinde kullanılmaktadır (Pollio ve ark., 2008). Son zamanlarda ise yapılan bir çalışmada, Kore'de toplanan $R$. chalepensis bitkisinin yapraklarından izole edilen quinoline bileşiğinin tip 2 şeker hastalığının (T2DM) tedavisine etkisi olduğu belirlenmiştir (Park ve Lee, 2015 Ayrıca parfüm sanayisinde kullanıldığ gibi insektisit aktivitesine sahip olduğu da bilinmektedir (Martínez-Pérez ve ark., 2017)

Bilindiği gibi serbest radikaller, enflamatuar yanıtın oluşumunu engelleyebildiğive beyin dokularında yaralanmaya neden olan proinflamatuar genlerin ekspresyonunu aktive edebildiği (Ramesh ve ark., 2013) gibi birçok kronik ve dejeneratif hastalıkların oluşmasına da sebep olmaktadır. Antioksidanlar, serbest radikallerin nötralizasyonu ile zararlı etkilerinin önlenmesinde önemli bir rol oynarlar. Antioksidanlar ayrıca demir ve bakır gibi geçiş metallerini tecrit ederek serbest radikallerin oluşumunu engelleyebilir. Reaktif serbest radikalleri azaltan veya tamamen süpürebilen bir antioksidan, diğer moleküllerin oksidasyonunu önleyebilir ve bu nedenle dejeneratif hastalıkların önlenmesinde sağlığı geliştirici etkiye sahip olabilir. Son zamanlarda gıda, kozmetik, tıp, eczacılık, tekstil gibi birçok sanayi dalında koruyucu ve katkı maddesi olarak kullanılan sentetik antioksidanların toksik ve kansorojen etkilerinin bulunduğu ortaya çıkarılmış, bunların yerine yüksek antioksidan aktivitesine sahip doğal ürünler/preparatlar tercih edilmeye başlamıştır (Pasqualon ve ark., 2015; Narayanasamy ve ark., 2018). Bitkisel kökenli doğal ekstraktlar, sentetik antioksidanlara alternatifler sağlamaktadır. Bu yüzden aromatik bitkilerden, baharatlardan ve meyve tozundan doğal antioksidan amaçlı ekstraktlar geliştirilmiş, geliştirmeye de devam edilmektedir (Bajaj ve ark., 2006, Shah ve ark., 2014).

$\mathrm{Bu}$ bağlamda, bu çalışmada geleneksel tıpta önemli yeri olan, Türkiye'de yetişen $R$. chalepensis ve $R$. montana türlerinin toprak üstü kısımlarının metanol ve etanol ekstraktlarının biyoaktif madde içerikleri ve radikal kovucu aktiviteleri incelenmiştir.

\section{MATERYAL ve METOD \\ Materyal}

Ruta chalepensis L. ve Ruta montana (L. türlerinin toprak üstü kısımları 2014 yılında çiçeklenme dönemlerinde sirasiyla C4 Antalya; Alanya bölgesinden ve A5 Amasya; Kirazlıdere mevkisinden toplanmıştır. , ; Örnekleme her türden 25 ayrı bitkiden yapılmıştır (Şekil 1). 


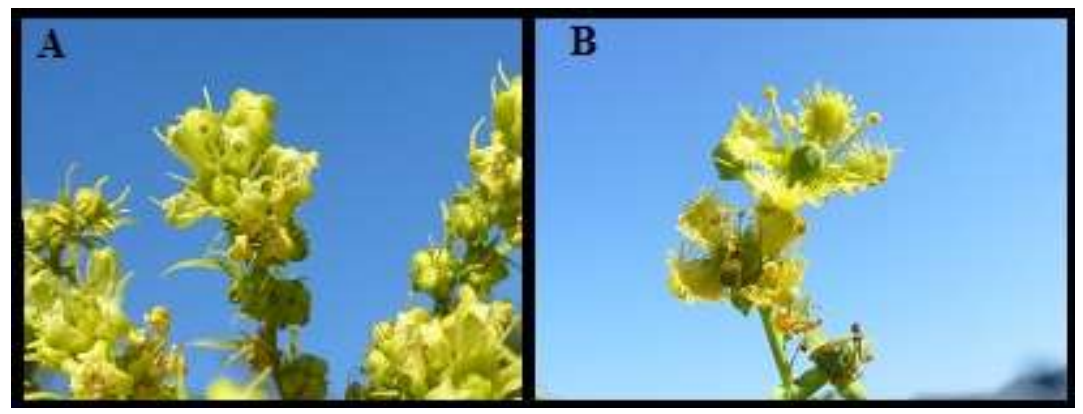

Şekil 1. Türlerin çiçekli durumda genel görüşünü Ruta montana (L.) L. (A) ve Ruta chalepensis L.. (B)

Türlerin teşhisleri Selçuk Üniversitesi, Eczacılık Fakültesi Öğretim Üyesi Prof. Dr. Osman Tugay ve Selçuk Üniversitesi, Fen Fakültesi Öğretim Üyesi Dr. Deniz Ulukuş tarafından yapılmış, $R$. montana için OT-7410-DU ve $R$. chalepensis için OT-9628-DU herbaryum numaraları verilmiştir.

\section{Ekstraksiyon}

Toplanan bitki örneklerinin toprak üstü kısımları gölgede kurutulmuş, $R$. montana türü çiçek-yaprak ve gövde kısımları olmak üzere iki parçaya ayrılmış, $R$. chalepensis toprak üstü aksamı kullanılmıştır. Elde edilen örnekler blender da öğütülmüştür. Örneklerden $5 \mathrm{~g}$ tartılıp üzerine $50 \mathrm{ml}$ metanol veya ethanol çözücüleri eklenmiştir. Her örnek için uygulamalar 3 tekrarlı olarak yapılmıştır. Karışımlar etüvde $40^{\circ} \mathrm{C}$ 'de 1 gün (24 saat) süre ile bekletilmiştir. Elde edilen çözeltiler santrifüj cihazında 4.500 rpm'de santrifüj edilmiştir. Süpernatan kısımları alınmış ve organik çözücü evaporatör yardımı ile ayrıştırılmış ve ekstraktların miktarları belirlenmiştir. (Çizelge 1). Ekstraktlar kullanılıncaya kadar $+4{ }^{\circ} \mathrm{C}$ 'de muhafaza edilmiştir.

Çizelge 1. R. montana ve $R$. chalepensis türlerinin etanol ve metanol çözücülerindeki ekstrakt verimleri

\begin{tabular}{lllc}
\hline Örnek Adı & Çözücü & \% & mg/g Kuru Madde \\
\hline RC & Metanol & 9.99 & $99.9 \pm 0.44$ \\
& Etanol & 4.89 & $48.9 \pm 1.67$ \\
\hline RM1 & Metanol & 15.11 & $151.1 \pm 0.78$ \\
& Etanol & 7.07 & $70.7 \pm 0.53$ \\
\hline RM2 & Metanol & 6.88 & $68.8 \pm 1.14$ \\
& Etanol & 2.67 & $26.7 \pm 0.50$ \\
\hline
\end{tabular}

\pm standart hata kullanılmıştır. n:3

\section{Toplam Biyoaktif İçerik \\ Toplam Fenolik Madde İçeriğinin Belirlenmesi (TF)(Folin Yöntemi)}

Ekstraktların toplam fenolik madde içeriği Singleton ve ark. (1999) metoduna göre belirlenmiştir. Çalışma için hazırlanmış $(2 \mathrm{mg} / \mathrm{ml})$ örnek çözeltilerinden $0.2 \mathrm{ml}$ alınmış ve üzerine $9 \mathrm{ml}$ distile su ilave edildikten sonra $0.2 \mathrm{ml}$ Folin Ciocalteu reaktifi eklenmiş, $3 \mathrm{dk}$ beklemeye birakılmıştır. Son olarak $0.6 \mathrm{ml} \mathrm{Na} \mathrm{CO}_{3}$ (\%20) ilave edilerek, toplam hacim $10 \mathrm{ml}$ olacak şekilde ayarlanmıştır. Oda sıcaklığında 2 saat karanlıkta inkübe ettikten sonra $760 \mathrm{~nm}$ 'de absorbans ölçümü yapılmıştır. Standart kalibrasyon eğrisi oluşturmada gallik asitten faydalanılmıştır. Ana stok olarak $0.1 \mathrm{mg} / \mathrm{ml}$ hazırlanmış ve seyreltme ile yedi farklı konsantrasyon elde edilmiştir. Kontrol için 0.2 $\mathrm{ml}$ örnek çözeltisi ilave edilmiştir. Gallik asit standart grafiğine göre tüm bitki ekstraktlarındaki toplam fenolik madde mg gallik asit eşdeğeri (GAE)/g ekstrakt olarak hesaplanmıştır. Her bir deneme 4 tekerrürlü olarak yapılmıştır.

\section{Toplam Flavonoid Madde İçeriğinin Belirlenmesi (TFL)}

Ekstraktların toplam flavonoid madde miktarları Arvouet-Grand ve ark. (1994) yöntemine göre yapılmıştır. Deneyin hazırlanışında \%10'luk alüminyum nitrattan $100 \mu \mathrm{l}, 1 \mathrm{M}$ potasyum asetattan $100 \mu \mathrm{l}$ alınıp bitki özütü son konsantrasyonu $100 \mu \mathrm{g} / \mathrm{ml}$ olacak şekilde ekstrakt ilave edilmiştir. Deneyin son hacimi \%99'luk etanol ile 5 ml'ye tamamlanmıştır. Oda sıcaklığında $40 \mathrm{dk}$ karanlıkta inkübe ettikten sonra 417 nm'de absorbans ölçümü yapılmıştır. Kontrol için ekstrakt yerine örnek çözeltisinden $200 \mu \mathrm{l}$ ilave edilmiştir. Kuersetin standartı için ana stok $0.5 \mathrm{mg} / \mathrm{ml}$ hazırlanmış ve seyreltme ile sekiz farklı konsantrasyon elde edilmiştir. Toplam flavonoid madde içeriği mg kuarsetin eşdeğeri (KE)/g ekstrakt olarak ifade edilmiştir. Her bir deneme 4 tekerrürlü olarak yapılmıştır.

\section{Radikal Kovucu Aktivite}

\section{DPPH Radikali Süpürücü Aktivite Tayini}

Ekstraktlarm serbest radikal aktiviteleri DPPH serbest radikali kullanılarak belirlenmiştir (Gezer ve ark., 2006). Deney için $4 \mathrm{mg} \mathrm{DPPH}, 100 \mathrm{ml}$ metanol içerisinde çözülerek deriş̧im hazırlanmıştır. Her bir örnek için $3.2 \mathrm{ml}$ DPPH radikali ve ekstrakt çözeltilerinden $200 \mu \mathrm{l}(500 \mu \mathrm{g} / \mathrm{ml})$ ilave edilmiştir. Oda sıcaklığında $30 \mathrm{dk}$ karanlıkta inkübe ettikten sonra $517 \mathrm{~nm}$ 'de absorbans ölçümü yapılmıştır. Kontrol için deney tüpüne $200 \quad \mu l$ ekstrakt çözücüsü ilave edilmiştir. Her bir deneme 3 tekerrürlü olarak 
yapılmış, her tekerrür iki tekrarlı olarak yapılmıştır. $\mathrm{DPPH}$ radikali süpürücü \%'sinin belirlenmesinde aşağıdaki formül kullanılmıştır.

$\%$ DPPH süpürücü aktivite $=\left[\left(\mathrm{A}_{\text {kontrol }}-\mathrm{A}_{\text {ekstrakt }}\right) / \mathrm{A}_{\text {kontrol }}\right] \times 100$

\section{ABTS Radikal Süpürücü Aktivite Tayini}

ABTS radikal kovucu aktivite Miller ve ark., (1993) ve Re ve ark., (1999)'nın yöntemleri modifiye edilerek belirlenmiştir. Kısaca ABTS radikali, $30 \mathrm{mg}$ ABTS ile $7.8 \mathrm{ml}$ distile su içerisinde $6.6 \mathrm{mg}$ çözünmüş potasyum persülfat karıştırılarak ve 12-16 saat oda sıcaklığında karanlıkta bekletilerek elde edilmiştir. Daha sonra ABTS 734 nm'de absorbans değeri $0.700 \pm 0.020$ olacak şekilde distile su ile seyreltilmiştir. Deney için $100 \mu \mathrm{l}$ (2 mg/ml) örnek üzerine $2.8 \mathrm{ml}$ ABTS solüsyonu eklenmiş, $30 \mathrm{dk}$ oda sicaklığında inkübe ettikten sonra 734 nm'de absorbans ölçümü yapılmıştır. ABTS radikal süpürücü aktivitesinin \% inhibisyon değeri aşağıdaki formül kullanılarak belirlenmiştir.

$\%$ ABTS süpürücü aktivite $=\left[\left(\mathrm{A}_{\text {kontrol}}-\mathrm{A}_{\text {ekstrakt }}\right) / \mathrm{A}_{\text {kontrol }}\right] \times 100$

\section{İstatistik Analizler}

Elde edilen verilere Düzgüneş ve ark. (1983) tarafından bildirildiği şekilde varyans analizi ANOVA prosedürüne göre yapilmıştır. Ortamalar arası fark Duncan kiyaslama testine göre $p<0.05$ ve $p<0.01$ seviyesinde değerlendirilmiştir. Yüzde değerler istatistiki analizden önce açı değerlerine dönüştürülerek (Snedecor ve Cochran 1967), varyans analizine tabi tutulmuştur. Ayrıca her bir örnek için TF, TFL, DPPH ve ABTS arasındaki ilişki korelesyon (Pearson) analizi ile belirlenmiştir. Elde edilen veriler ortalama \pm standart hata olarak verilmiştir.

\section{BULGULAR ve TARTIŞMA}

\section{Toplam bioaktif madde içerikleri}

Ruta L. türlerinin metanol ve etanol çözücülerinden elde edilen ekstraktlarının toplam bioaktif madde (toplam fenolik ve flavonoid madde) içerikleri spektrofotometrik yöntemle belirlenmiş ve sonuçlar Çizelge 2'de verilmiştir.

Toplam fenolik içerik Folin yöntemine göre gallik asit eşdeğeri olarak hesaplanmıştır. İki farklı çözücüde hem ekstraktın hem de kuru madde miktarının toplam fenolik içerikleri tespit edilmiştir.

Örneklerin TF içeriği $1 \mathrm{~g}$ ekstrakta $38.05 \pm 0.06$ ila $54.10 \pm 0.13 \mathrm{mg} \mathrm{GAE} / \mathrm{g}$ ekstrakt arasında değiştiği ve istatistiki olarak farklılık bulunduğu belirlenmiştir. En yüksek TF içerik etanol RC ekstraktlarında $54.10 \pm 0.13 \mathrm{mg}$ GAE/g ekstrakt olarak bulunmuş ve metanol RM2 53.55 $\pm 0.07 \mathrm{mg}$ GAE/g ekstrakt ile istatistiki olarak aynı grupta yer almıştır. Bunu sirasiyla etanol RM2 49.63 \pm 0.11 , metanol RM1

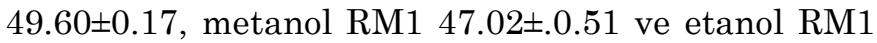
$38.05 \pm 0.06 \mathrm{mg}$ GAE/g ekstrakt izlemiştir. Ayrıca etanol RM2 ve metanol RM1 istatistiki olarak $\mathrm{p}<0.05$ ve $\mathrm{p}<0.01$ seviyelerinde aynı grupta yer almıştır.

TF içerik $1 \mathrm{~g}$ kuru maddede $7.11 \pm 0.08$ ila $1.32 \pm 0.00 \mathrm{mg}$ GAE/g kuru madde olarak saptanmıştır. En yüksek TF içerik metanol RM1M 7.11 $\pm 0.08 \mathrm{mg}$ GAE/g kuru madde ve bunu sirasiyla metanol RC > metanol RM2 > etanol $\mathrm{RM} 1=$ etanol $\mathrm{RC}>$ etanol RM2 takip ettiği belirlenmiştir.

Çizelge 2. $R$. montana ve $R$. chalepensis ekstraklarının toplam fenolik ve flavonoid içerikleri

\begin{tabular}{llllll}
\multirow{2}{*}{ Çözücü } & \multirow{2}{*}{ Toplam Fenolik İçerik } & \multicolumn{2}{l}{ Toplam Flavonoid İçerik } \\
\cline { 3 - 6 } & Örnekler & mg GAE/g ekstrak & mg GAE/g KA & mg KE/g ekstrak & $\mathrm{mg} \mathrm{KE} / \mathrm{g} \mathrm{KA}$ \\
\hline \multirow{2}{*}{ Metanol } & RC & $49.60 \pm 0.17 \mathrm{bB}$ & $4.96 \pm 0.02 \mathrm{bB}$ & $47.53 \pm 0.19 \mathrm{aA}$ & $4.75 \pm 0.02 \mathrm{bB}$ \\
& RM1 & $47.02 \pm .0 .51 \mathrm{cC}$ & $7.11 \pm 0.08 \mathrm{aA}$ & $32.70 \pm 0.16 \mathrm{cB}$ & $4.94 \pm 0.02 \mathrm{aA}$ \\
& RM2 & $53.55 \pm 0.07 \mathrm{aA}$ & $3.63 \pm 0.00 \mathrm{cC}$ & $18.94 \pm 0.24 \mathrm{eD}$ & $1.30 \pm 0.02 \mathrm{eE}$ \\
\hline \multirow{2}{*}{ Etanol } & RC & $54.10 \pm 0.13 \mathrm{aA}$ & $2.65 \pm 0.01 \mathrm{dD}$ & $46.89 \pm 0.16 \mathrm{bA}$ & $2.29 \pm 0.01 \mathrm{cC}$ \\
& RM1 & $38.05 \pm 0.06 \mathrm{dD}$ & $2.69 \pm 0.00 \mathrm{dD}$ & $27.71 \pm 0.08 \mathrm{dC}$ & $1.96 \pm 0.01 \mathrm{dD}$ \\
& RM2 & $49.63 \pm 0.11 \mathrm{bB}$ & $1.32 \pm 0.00 \mathrm{eE}$ & $7.24 \pm 0.04 \mathrm{dF}$ & $0.19 \pm 0.00 \mathrm{fF}$ \\
\hline
\end{tabular}

RC: $R$. chalepensis ekstraktı, RM1: $R$. montana çiçek-yaprak ekstraktı, RM2: $R$. montana gövde ekstraktı, istatistiksel olarak her sütun ayrı değerlendirilmiş ve farklılıklar $\mathrm{p}<0.05$ seviyesine göre küçük harfle/ $\mathrm{p}<0.01$ seviyesine göre büyük harfle belirtilmiştir.

Toplam flavonoid içerik kuarsetin eşdeğer olarak hesaplanmıştır. İki farklı çözücüde hem ekstraktın hem de kuru madde miktarının toplam flavanoid içerikleri tespit edilmiştir. Örneklerin TFL içeriği $1 \mathrm{~g}$ ekstrakta $47.53 \pm 0.19$ ila $7.24 \pm 0.04 \mathrm{mg} \mathrm{KE} / \mathrm{g}$ ekstrakt olarak değişmiş ve istatistiki olarak farklılık bulunduğu belirlenmiştir. En yüksek TFL içerik metanol ve etanol RC ekstraktindan, sirasiyla $47.53 \pm 0.19 \mathrm{mg} \mathrm{KE} / \mathrm{g}$ ve $46.89 \pm 0.16 \mathrm{mg} \mathrm{KE} / \mathrm{g}$ olarak elde edilmiştir. İstatistiki olarak $\mathrm{p}<0.05$ seviyesinde anlamlı farklılık gözlenirken, $\mathrm{p}<0.01$ seviyesinde farklılık olmadığı tespit edilmiştir. Bunu sırasıyla metanol RM1 > etanol RM1 > metanol RM2> etanol RM2 takip etmiştir.

TFL içerik $1 \mathrm{~g}$ kuru maddede ise $4.94 \pm 0.02$ ila $0.19 \pm 0.00 \mathrm{mg} \mathrm{KE} / \mathrm{g}$ kuru madde olarak değişiklik göstermiş ve örnekler arasında istatistiki farklılıklar olduğu gözlenmiştir. En yüksek TFL içerik metanol RM1 ve RC ekstraklarinda sirasiyla $4.94 \pm 0.02$ ve $4.75 \pm 0.02 \mathrm{mg} \mathrm{KE} / \mathrm{g}$ kuru madde belirlenmiş ve 
istatistiki fark olduğu saptanmıştır $(\mathrm{p}<0.05, \mathrm{p}<0.01)$. Diğer örneklerdeki TFL içerik bakımından sırasıyla etanol RC> etanol RM1> metanol RM2> etanol RM2 azalma olduğu tespit edilmiştir.

Ruta chalepensis L. (toprak üstü kısmı) ve $R$. montana L. (yaprak-çiçek ve gövdekısımları) türlerinin metanol ve etanol ekstraklarının TF ve TFL içerikleri incelenmiştir. Fenolik bileşim bakımından 54.10 \pm 0.13 mg GAE/g ekstrakt ile etanol Ruta chalepensis ekstraktı ve $53.55 \pm 0.07 \mathrm{mg}$ GAE/g ekstrakt ile metanol $R$. montana L. (gövde kısımları) içerik bakımından en zengin ekstrakt olarak bulunmuştur. Fakat örneklerin kuru ağırlıkları değerlendirdiğinde en yüksek TF içerik $7.11 \pm 0.08 \mathrm{mg}$ GAE/g ile metanol $R$. montana L. (yaprak-çiçek kısımları) örneklerinde olduğu tespit edilmiştir.

TFL içerik en fazla Ruta chalepensisin metanol ve etanol ekstraktından elde edilmiştir. Fakat örneklerin kuru ağırlıkları değerlendirdiğinde en yüksek $R$. montana L. (yaprak-çiçek kısımları) metanol ekstraktlarında bulunmuştur. Örneklerin g ekstrakt ve kuru ağırlık içerisindeki TF ve TFL içeriklerinin farklı olması örneklerin ekstraksiyon veriminden kaynaklanmaktadır. Genel olarak, metanol ekstraktları etanol ekstraklarına göre daha fazla toplam fenolik ve flavonoid içeriklere sahip olmuştur.

Ruta chalepensis türünün farklı ekstraktlardaki TF ve TFL içeriği hakkında birçok çalışma bulunmaktadır. $\mathrm{Bu}$ çalışmadaki türlerin Türkiye lokalitesine ait olması, diğer çalışmalardan farklı kılmaktadır. Bu çalışma sonuçlarına benzer olarak Fakhfakh ve ark. (2012) TF içeriğini etanol ekstraktında $54.13 \mathrm{mg}$ GAE/g ekstrakt bulmuşlardır. Gali ve Bedjou (2018) en yüksek TF içeriği $210.00 \pm 4.93 \mu \mathrm{g}$ GAE/mg ekstrakt ile butanol ekstratında bulmuş, hatta etil asetat ekstraktında etanol (61.61 $\pm 0.70 \mu \mathrm{g} \mathrm{GAE} / \mathrm{mg}$ ekstrakt) ekstraktından daha fazla olduğunu rapor etmişlerdir. Kacem ve ark. (2015) etanol, su, hekzan, etil asetat çözücülerinden en yüksek TF içeriği $178 \mathrm{mg}$ GAEs/g ekstrakt ile etanol ekstraktından elde etmişlerdir. Ouerghemmi ve ark. (2017) Ruta chalepensis bitkisinin farklı kısımlarına ait metanol örneklerin TF içeriklerini 0.2 ile $168.91 \mathrm{mg}$ GAE/g kuru ağırlık olarak bildirmişlerdir. Ereifej ve ark. (2015) metanol ekstraktın TF içeriğini 1328.8 mg GAE/100 g kuru ağırlık bulmuşlardır. Değerler arasındaki farklılığın lokalite ve ekstraksiyon yöntemlerinden kaynaklandığı düşünülmüştür. Son zamanlardaki bir çalışmada, Loizzo ve ark. (2018) $R$. chalepensis yaprak kısmının etanol ekstraktında TF içeriğini $6.22 \mathrm{mg}$ GAE/g KA ve TFL içeriğini $6.59 \mathrm{mg} \mathrm{KE} / \mathrm{g} \mathrm{KA}$ olarak rapor etmişlerdir. $\mathrm{Bu}$ çalışmadaki $R$. chalepensis örneklerinin aynı çözücüdeki herba ekstaktlarının TF ve TFL içeriğinin kuru madde olarak değerlendirildiğinde daha düşük değerlere sahip olduğu (sırasiyla, $2.65 \mathrm{mg} \mathrm{GAE} / \mathrm{g} \mathrm{KA}$ ve $2.29 \mathrm{mg} \mathrm{KE} / \mathrm{g}$ KA) saptanmıştır. $\mathrm{Bu}$ farklılığın bitkinin farklı kısımlarının kullanılmasından kaynaklandığı düşünülmektedir. Fakat yüksek oranda TFL içeriğine sahip olmasının, bu çalışma sonuçları ile benzer olduğu gözlenmiştir. Ouerghemmi ve ark. (2017) in vivo ve kültür Ruta chalepensis bitkisinin farklı kısımlarına ait metanol örneklerin 0.1 ila $50 \mathrm{mg}$ kateşin eşdeğer/g kuru ağırlık arasında olduğunu bildirmiştir. Ruta montana türü için, Khadhri ve ark. (2017) etanol gövde ekstraktların yaprak ekstraktlarından daha fazla TF içeriğe sahip olduğunu tespit etmişlerdir. $\mathrm{Bu}$ çalışmadaki $R$. montana türünün kuru ağırlığındaki TF içeriği ile benzer olduğu gözlenmiştir.

\section{Radikal Kovucu Aktivite}

Flavonoidler, polifenoller, tanenler ve diğer fenolikler gibi bitkilerin çeşitli fitokimyasalları (sekonder metabolitleri), serbest radikal kovucular olarak hizmet eden bileşenlerin ana grubudur. Bu çalışmada iki farklı Ruta L. türünün etanol ve metanol çözücülerinden elde edilen ekstraktlarının ABTS ve DPPH radikallerini süpürme aktivitesi incelenmiştir. Sonuçlar \% inhibisyon olarak ifade edilmiştir.

DPPH radikali, reaksiyon kolaylığı nedeniyle serbest radikal kovucu aktivitesinin değerlendirilmesinde büyük ölçüde kullanılmaktadır. DPPH radikali, stabil bir DPPH-H molekülü oluşturmak için hidrojen bağışı yoluyla bir antioksidan bileşiği ile temizlendiğinde, çözeltinin rengi mordan sarıya döner (Gangwar ve ark., 2014). Mevcut çalışmada $100 \mu \mathrm{g} / \mathrm{ml}$ ekstraktların kararlı mor DPPH radikalini sarıya dönüştürdüğü tespit edilmiştir. En güçlü aktivite metanol RC ekstraktında \% 80.1 bunu sirasiyla metanol RM1, etanol RC, metanol RM2, etanol RM1 ve RM2 takip etmiştir. En düşük aktivite \% 61.1 ile etanol RM2 ekstraktında gözlenmiştir (Şekil 2). İstatistiki olarak her bir ekstrakt arasında anlamlı farklılıklar olduğu belirlenmiştir $(\mathrm{p}<0.05, \mathrm{p}<0.01)$.

ABTS radikali mavi renkli olup, maviden renksiz forma bir antioksidan bileşik ile dönüşmektedir (Boligon ve ark., 2014). Şekil 3'te görüldüğü üzere, ABTS radikal kovucu aktivitesi, değerlendirilen tüm ekstraktlarm $200 \mathrm{ug} / \mathrm{ml}$ lik konsantrasyonunda \% 54.81 -\% 40.35 arasında değişmiştir. En yüksek değer $\% 54.81$ ile etanol RC ekstraktında belirlenmiş ve diğer ekstraktlarla aralarında anlamlı farklılıklar gözlenmiştir. Bunu \% 48.81 ile metanol RC ekstraktı, \% 48.22 ile etanol RM2, \% 45.87 ile metanol RM1, \% 43.83 ile metanol RM2 takip etmiş ve istatistiki olarak aynı grupta yer aldığ 1 belirlenmiştir $(p<0.01)$. En düşük aktivite ise $\% 40.35$ ile etanol RM2 ekstraktlarında tespit edilmiştir

En çok kullanılan radikal kovucu aktivitelerden olan DPPH ve ABTS aktiviteleri sirasiyla $100 \mu \mathrm{g} / \mathrm{ml}$ ve 200 $\mu \mathrm{g} / \mathrm{ml}$ konsantrasyonlarda incelenmiştir. Her iki radikal için en güçlü aktivite metanol Ruta chalepensis ekstraktında belirlenmiştir. ABTS 
radikali için ise metanol $R$. montana L. (yaprak-çiçek kısımları) örneklerin ekstraktında, Ruta chalepensis ve $R$. montana L. (gövde kısımları) örneklerinde ise etanol ekstraktları daha fazla aktiviteye sahip olduğu gözlenmiştir.

DPPH için tüm örneklerin metanol ekstraklarının etanol ekstraktlarına göre daha etkili olduğu tespit edilmiştir. Ruta chalepensis türü hakkında yapılan bir çalışmada yaprak örneklerinin etanol ekstraktın sulu ekstrakt ile sentetik standart olan bütil hidroksi toluen'den daha düşük ve uçucu yağ örneklerinden ise daha yüksek radikal kovucu aktiviteye sahip olduğu vurgulanmıştır (Fakhfakh ve ark., 2012). Fakat diğer bir çalışmada $R$. chalepensis türünün yaprak-gövde örneğinin etanol ekstraktının su, etil asetat ve hekzan ekstraktından daha fazla radikal kovucu aktivitesine sahip olduğunu, hatta sulu ekstrakt aktivitesinin etil asetat ekstraktından daha az olduğunu bildirmiştir (Kacem ve ark., 2015). Ayrica Kacem ve ark. (2015) ekstraktların farklı konsantrasyonlarada radikal kovucu aktivitesini incelemişler ve etanol ekstraktın $0.125 \mathrm{mg} / \mathrm{ml}$ örneğinin \% inhibisyonunu yaklaşık \%8070 arasında bulmuşlardır. Bu değerin bu çalışma ile örtüştüğü gözlenmiştir. Gali ve Bedjou (2018) bu çalışmadaki ile benzer ektraksiyon yöntemi kullanmış ve $R$. chalepensis türünün toprak üstü etanol ekstraktının, bütanol ile etil asetat ekstraktlarından daha düşük aktivite sergilediğini bildirmişlerdir.

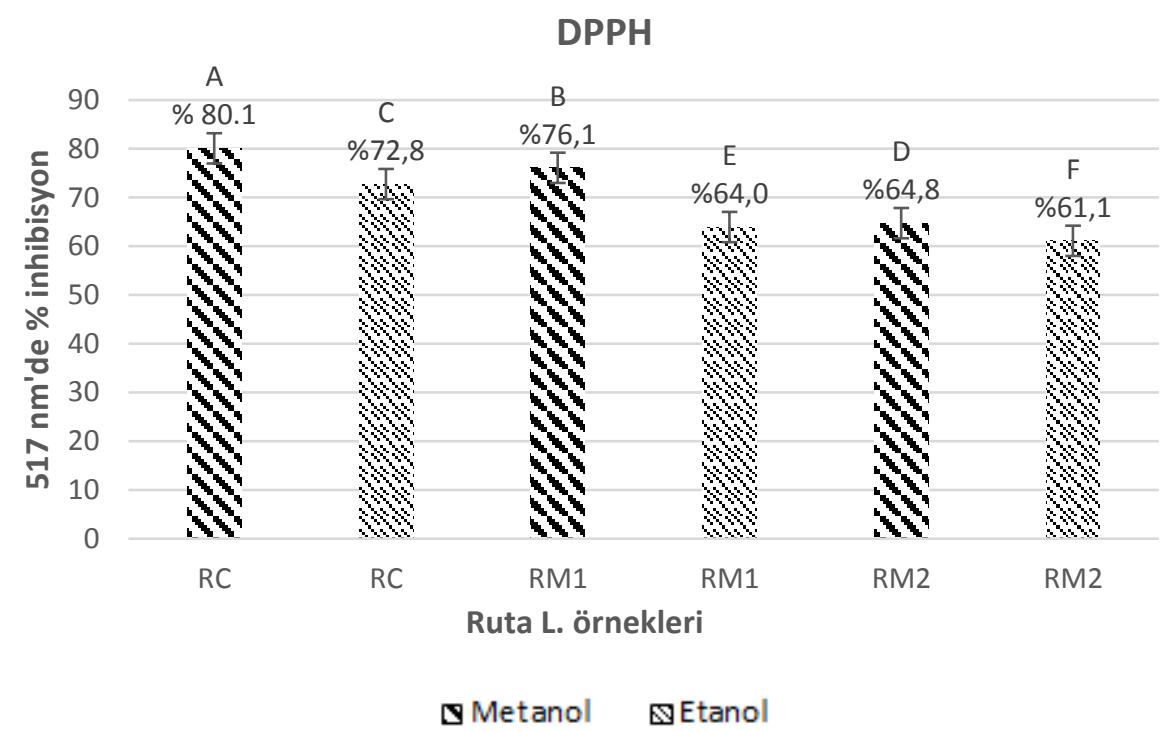

Şekil 2. $R$. montana ve $R$. chalepensis ekstraklarının DPPH serbest radikal kovucu aktivitesi. RC: $R$. chalepensis, RM1: $R$. montana çiçek-yaprak ekstraktı, RM2: $R$. montana gövde ekstraktı. İstatiksel olarak ortalamalar arasındaki fark $\mathrm{p}<0.01$ seviyesine göre büyük harfle sütun üzerlerinde belirtilmiştir.

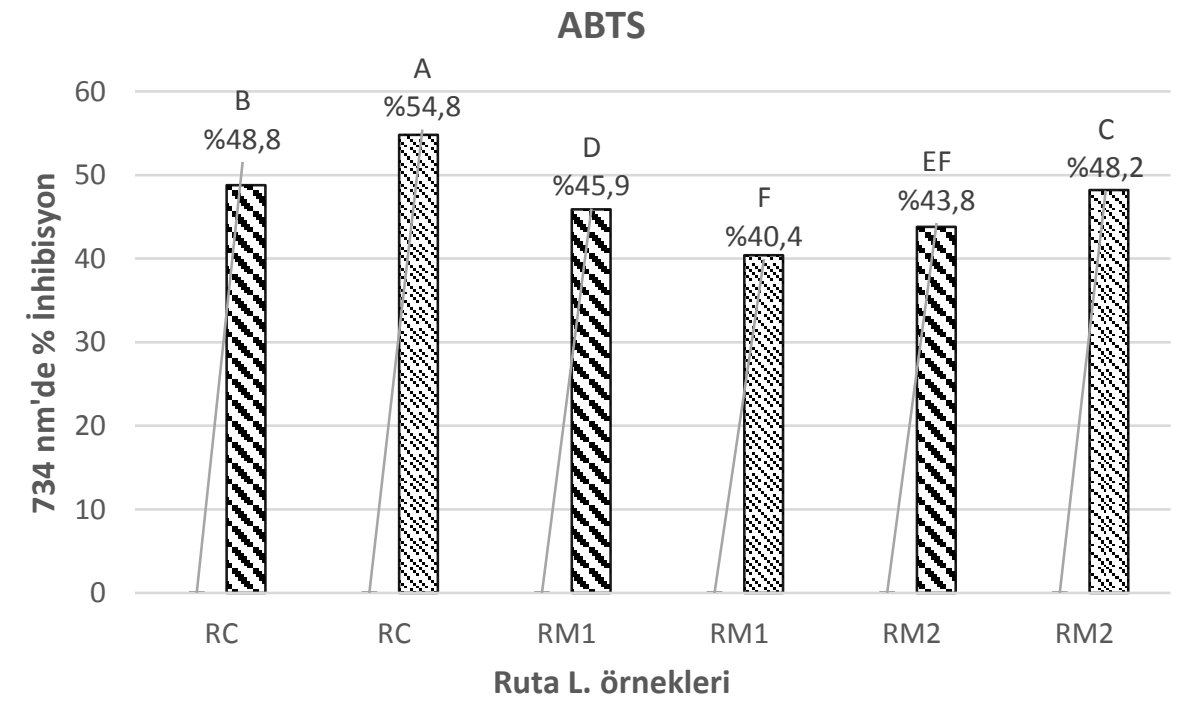

\section{\$Metanol $\mathbf{E}$ Etanol}

Şekil 3. $R$. montana ve $R$. chalepensis ekstraklarının ABTS serbest radikal kovucu aktivitesi. RC: $R$. chalepensis, RM1: $R$. montana çiçek-yaprak ekstraktı, RM2: $R$. montana gövde ekstraktı. İstatiksel olarak ortalamalar arasındaki fark $p<0.01$ seviyesine göre büyük harfle sütun üzerlerinde belirtilmiştir. 
Ouerghemmi ve ark. (2017) $R$. chalepensis türünün en yüksek DPPH aktivitesinin sırasıyla çiçek, yaprak ve gövde metanol ekstraktlarında olduğunu rapor etmişlerdir. Bu çalışma ile benzer olarak $R$. montana türünün her iki çözelti için de yaprak-çiçek ekstraktları gövde ekstraktlarından daha yüksek DPPH aktivitesine sahip olduğu saptanmıştır.

\section{Korelasyon}

Toplam biyoaktif içerikler ile radikal kovucu aktiviteler arasındaki ilişkiler yapılan istatistiki analizle önemli bulunmuştur (Çizelge 3). Etanol ve metanollü her bir ekstraktın TF/TFL, TF/DPPH, TF/ABTS, TFL/DPPH ve TFL/ABTS etkileşimleri ayrı ayrı değerlendirilmiştir.
Metanol RC ekstraktının TF içeriği TFL, DPPH ve ABTS üzerine negatif korelasyon etkiye sahip olduğu ve istatistiki bir öneme sahip olmadığ gözlenmiştir. Fakat TFL içeriği ile DPPH ve ABTS üzerine yüksek derecede pozitif etkiye sahip olduğu ve TFLxDPPH arasında istatistiki olarak 0.05 seviyesinde önemli olduğu tespit edilmiştir $(\mathrm{r}=0.987)$.

Etanol RC ekstraktın da TF içeriği TFL, DPPH ve ABTS üzerine yüksek derecede negatif korelasyon etkiye $(\mathrm{r}=0.978)$ sahip olduğu ve TFxDPPH arasında istatistiki olarak 0.05 seviyesinde önemli olduğu saptanmıştır. TF içeriğinin $\mathrm{DPPH}$ ve ABTS üzerine pozitif etki gösterdiğini ve istatistiki fark olmadığ gözlenmiştir.

Çizelge 3. Ruta L. bitkilerinin etanol ve metanol ekstraktlarının toplam bioaktif bileşikleri ile radikal kovucu aktiviteler arasındaki korelasyon

\begin{tabular}{lllcc}
\hline Çözücü & Örnekler & TFL & DPPH & ABTS \\
\hline \multirow{3}{*}{ Metanol } & TF & & & -0.605 \\
& RC & -0.770 & -0.824 & 0.185 \\
& RM1 & -0.888 & 0.192 & 0.252 \\
\hline \multirow{2}{*}{ Etanol } & RM2 & $-0.999^{* *}$ & 0.888 & -0.899 \\
& RC & -0.711 & $-0.978^{*}$ & -0.301 \\
\hline & RM1 & -0.675 & -0.571 & -0.522 \\
\hline \multirow{2}{*}{ Metanol } & RM2 & -0.289 & $0.951^{*}$ & 0.948 \\
& TFL & & $0.987^{*}$ & 0.279 \\
\hline \multirow{2}{*}{ Etanol } & RC & & 0.276 & -0.295 \\
& RM1 & & -0.900 & 0.406 \\
& RM2 & & 0.551 & -0.169 \\
\hline & RC & 0.988 & -0.364 \\
\hline
\end{tabular}

* Korelasyonun 0.05 seviyesinde önemli, ** Korelasyonun 0.01 seviyesinde önemli

Metanol RM1 ekstraktın TF içeriğinin TFL içeriği üzerine yüksek derecede negatif etkiye sahip olduğu $(\mathrm{r}=0.999)$ ve istatistiki olarak 0.01 seviyesinde önemli olduğu tespit edilmiştir. Li ve ark. (2012) yapmış oldukları çalışmalarında, TF ve TFL arasında pozitif bir korelasyon ( $r=0.685$ ) olduğunu bildirmiş̧lerdir. DPPH ve ABTS üzerine ise pozitif etki gösterdiği ve istatistiki fark olmadığı gözlenmiştir. Benzer şekilde TFL içeriğin DPPH ve ABTS üzerinde pozitif etkiye sahip olduğu ve istatistiki bir fark olmadığ belirlenmiştir.

Etanol RM1 ekstraktın TF içeriği TFL, DPPH ve ABTS üzerine negatif etkiye sahip olduğu, TFL içeriğin DPPH üzerine yüksek derecede pozitif etkiye ve ABTS üzerine de negatif etkiye sahip olduğu ve uygulamalar arasında istatistiki bir fark olmadığı belirlenmiştir.

Metanol RM2 ekstraktının TF içeriğinin TFL, DPPH ve ABTS üzerine, TFL içeriğinin ise $D P P H$ ve ABTS üzerine negatif etkiye sahip olduğu ve istatistiki fark olmadiğı gözlenmemiştir.

Etanol RM2 ekstraktının TF içeriğin TFL ve ABTS üzerine negatif korelasyon etkiye sahip olduğu ve istatistiki bir öneme sahip olmadığı saptanmıştır. Fakat DPPH üzerine yüksek derece pozitif etkiye $(\mathrm{r}=$ 0.951) sahip olduğu ve istatistiki olarak 0.05 seviyesinde önemli olduğu belirlenmiştir. Birçok çalışma, TF ve antioksidan arasında pozitif ve negatif korelasyon olabileceğini göstermiştir (Katalinic ve ark., 2006; Ahn ve ark. 2007; Jastrzebski ve ark. 2007; Kettawan ve ark. 2011). TFL içeriği ile DPPH ve ABTS arasında negatif etkiye sahip olduğu ve istatistiki fark olmadığı gözlenmiştir.

\section{SONUÇ}

Türkiye florasindan toplanan $R$. chalepensis ve $R$. montana türlerinin yüksek oranda TF ve TFL içerdikleri gözlenmiştir. Her iki tür için de metanol ekstraktlarının ekstraksiyon verimi ile TF ve TFL içeriklerinin etanol ekstraktlarına göre daha yüksek olduğu tespit edilmiştir. Benzer sonuç ekstraktların DPPH aktivitesinde de gözlenmesine rağmen, ABTS aktivitesinde sadece $R$. montana türünün çiçek-yaprak ekstraktında gözlenmiştir. $\mathrm{Bu}$ çalışmadaki $R$. 
chalepensis ve $R$. montana türlerinin kendi aralarında ve diğer çalışmalarla arasındaki varyasyonların sebebinin tür, organ, fizyolojik yaş, hasat zamanı, lokalite gibi biyokimyasal ve fizyolojik yapılarını etkileyen farklılıklardan kaynaklandığı düşünülmüştür. Fakat buna rağmen bitkilerin yüksek oranda radikal kovucu aktiviteye sahip olduğu belirlenmiştir. Elde edilen sonuçlara göre geleneksel tıpta günümüzde dahi aktif olarak kullanılan bu türlerin gida, kozmetik ve farmakoloji gibi alanlarda doğal antioksidan kaynağı olarak tedavide, koruyucu ve katkı maddesi gibi kullanılabileceği düşünülmektedir.

\section{TEŞEKKÜR}

Bitki örnekleri Selçuk Üniversitesi Bilimsel Araştırma Projeleri koordinatörlüğü tarafından desteklenen proje (Proje no: 13201023) sayesinde toplanmıştır. Desteklerinden dolayı teşekkür ederiz.

\section{KAYNAKÇA}

Aguilar-Santamaria L, Tortoriello J 1995. Anticonvulsant and sedative effects of crude extracts of Ternstroemia pringlei and Ruta chalepensis. Phytother Res, 10:531e3.

Ahn J, Grün IU, Mustapha A 2007. Effects of plant extracts on microbial growth, color change, and lipid oxidation in cooked beef. Food Microbiology, 24:7-14.

Al-Said MS, Tariq M, Al-Yahya MA, Rafatullah S, Ginnawi OT, Ageel AM 1990. Studies on Ruta chalepensis, an ancient medicinal herb still used in traditional medicine. J Ethnopharmaeol., 28:305312.

Bajaj S, A. Urooj, Prabhasankar P 2006. Effect of incorporation of mint on texture, colour and sensory parameters of biscuits. International Journal of Food Properties, 9:691-700.

Bejar E, Bussmann R, Roa C, Sharon, D 1997. Herbs of Southern Ecuador. A Field Guide to the Medicinal Plants of Vilcabamba. Rodale Press, 256257.

Boligon AA, Machado MM, Athayde ML 2014. Technical Evaluation of Antioxidant Activity. Medicinal chemistry, 4(7):517-522.

Caleja C, Barros L, Antonio AL, Ciric A, Barreira JCM, Soković M, ve ark. 2015.Development of a functional dairy food: Exploring bioactive and preservation effects of chamomile (Matricaria recutita L.). Journal of Functional Foods, 16:114124.

Di Stasi LC, Hiruma CA, Guimaraes CM 1994. Medicinal plants used in Brazilian Amazon. Fitoterapia, 65:529-540.

El Guiche R, Tahrouch S, Amri O, El Mehrach K, Hatimie A 2015. Antioxidant activity and total phenolic and flavonoid contents of 30 medicinal and aromatic plants located in the South of Morocco. Int J New Technol Res., 1(3):7-11.

Ereifej, K.I., Feng, H., Rababah, T., Almajwal, A., Alủdatt,M., Gammoh, S.I., Oweis, L.I., 2015. Chemical composition, phenolics, anthocyanins concentration and antioxidant activity of ten wild edible plants. Food and Nutrition Sciences 6:581590.

Fakhfakh N, Zouari S, Zouari M, Loussayef C, Zouari $\mathrm{N}$ 2012. Chemical composition of volatile compounds and antioxidant activities of essential oil, aqueous and ethanol extracts of wild Tunisian Ruta chalepensis L. (Rutacea). Journal of Medicinal Plant Research, 6:593-600.

Forment M, H Roques 1941. Répertoire desplantes médicinales et aromatiques d'Algérie. Ed. OFALAC, 59.

Gali L, Bedjou F 2018. Antioxidant and anticholinesterase effects of the ethanol extract, ethanol extract fractions and total alkaloids from the cultivated Ruta chalepensis, South African Journal of Botany, https://doi.org/10.1016/ j.sajb.2018.04.011.

GangwarM, Gautam MK, Sharma AK, Tripathi YB, Goel RK, Nath G 2014. Antioxidant Capacity and Radical Scavenging Effect of Polyphenol Rich Mallotus philippenensis Fruit Extract on Human Erythrocytes: An In Vitro Study. Scientific World Journal., 12.

Gonzalez-Trujano ME, Carrera D, Ventura-Martinez R, Cedillo-Portugal E, Navarrete A 2006. Neuropharmacological profile of an ethanol extract of Ruta chalepensis L. in mice. J Ethnopharmacol., 106:129-135.

Günaydin K, Göycıncık S 2005. Phytochemical studies on Ruta chalepensİs (LAM.) lamarck. Natural Product Research, 19(3):203-210.

Iauk L, Mangano K, Rapisarda A, Ragusa S, Maiolino L, Musumeci R, Costanzo R, Serra A, Speciale A 2004. Protection against murine endotoxemia by treatment with Ruta chalepensis L., a plant with anti-inflammatory properties. J Ethnopharmacol., 90:267-272.

Jastrzebski Z, Medina OJ, Moreno LM, Gorinstein S 2007. In vitro studies of polyphenol compounds, total antioxidant capacity and other dietary indices in a mixture of plants (Prolipid). International Journal of Food Sciences and Nutrition, 58:531541.

Kacem M, Kacem I, Simon G, BenMansour A, Chaabouni S, Elfeki A, Bouaziz M 2015. Phytochemicals and biological activities of Ruta chalepensis L. growing in Tunisia. Food Bioscience, 12:73-83.

Kacem M, Simon G, Leschiera R, Misery L, ElFeki A, Lebonvallet $\mathrm{N}$ 2014. Antioxidant and antiinflammatory effects of Ruta chalepensis L. 
extracts on LPS-stimulated RAW 264.7 cells. In Vitro Cell Dev Biol Anim., 51:128-141.

Katalinic V, Milos M, Kulisic T, Jukic M 2006. Screening of 70 medicinal plant extracts for antioxidant capacity and total phenols. Food Chemistry, 94:550-557.

Kettawan A, Chanlekha K, Kongkachuichai R, Charoensiri R 2011. Effect of cooking on antioxidant activities and polyphenol content of edible mushrooms commonly consumed in Thailand. Pakistan Journal of Nutrition, 10:10941103.

Khadhri A, Bouali I, Belkhir S, Mokded R, Smiti S, Falé P, Eduarda M, Araújo M, Luisa M, Serralheiro M 2017. Invitro digestion, antioxidant and antiacetylcholinesterase activities of two species of Ruta: Ruta chalepensis and Ruta montana. Pharmaceutical Biology, 55(1):101-107.

Kubitzki K, Kallunki JA, Duretto M, Wilson PG 2011. Rutaceae. In: Kubitzki, K. (Ed) The families and genera of vascular plants. Vol. 10, Springer Verlag, Berlin, 276-356.

Khlifi D, Sghaier RM, Amouri S, Laouini D, Hamdi M, Bouajila J 2013. Composition and anti-oxidant, anti-cancer and anti-inflammatory activities of Artemisia herba-alba, Ruta chalpensis L. and Peganum harmala L. Food Chem Toxicol., 55:202208.

Li P, Sun W, Luo C, Shan T, Mou Y, Lu S, Mao Z, Zhou L 2012. In vitro evaluation of antioxidant activities of polysaccharides from the endophytic fungus Berkleasmium sp. Dzf12. African Journal of Microbiology Research 6:471-477.

Loizzo MR, Falco T, Bonesi M, Sicari V, Tundis R, Bruno M 2018. Ruta chalepensis L. (Rutaceae) leaf extract: chemical composition, antioxidant and hypoglicaemic activities. Natural Product Research, 32(5):521-528.

Mansour SS, Tarik MY, Rafatullah MAS, Ginnawi OT, Ageel AM 1990. Studies on Ruta chalepensis, an ancient medicinal herb still used in traditional medicine. J Ethnopharmacol., 28:305-312.

Martínez-Pérez EF, Hernández-TeránF, SerranoGallardoLB 2017. In Vivo Effect Of Ruta chalepensis extract On Hepatic Cytochrome 3A1 In Rats. Afr J Tradit Complement Altern Med., 14(4):62-68.

Morton CM, Telmer C 2014. New Subfamily Classification for the Rutaceae. Annals of the Missouri Botanical Garden, 99(4):620-641.

Narayanasamy B, Jeyakumar N, Manoharan DK 2018. Effect of natural antioxidants on the oxidation stability of methyl ester of rubber seed oil. Journal Energy Sources, Part A: Recovery, Utilization, and Environmental Effects, 40 (6):680687.

Ouerghemmi I, Rebey IB, Rahali FZ, Bourgou S, Pistelli L, Ksouri R, Marzouk B, TounsiMS 2017.
Antioxidant and antimicrobial phenolic compounds from extracts of cultivated and wild-grown Tunisian Ruta chalepensis. Journal of Food and Drug Analysis, 25(2):350-359.

Park JH, Lee HS 2015. Inhibitory effects of quinoline isolated from Ruta chalepensis and its structurally related derivatives against $\alpha^{-a m y l a s e}$ or $\alpha^{-}$ glucosidase. J Appl Biol Chem., 58:5-8.

Pasqualone A, Bianco AM, Paradiso VM, Summo C, Gambacorta G, Caponio F, Blanco A 2015. Production and characterization of functional biscuits obtained from purple wheat. Food Chemistry, 180:64-70.

Perry LM 1980. Medicinal Plants of East and Southeast Asia. The MIT Press, Boston, MA, pp. 368.

Pollio A, De Natale A, Appetiti E, Aliotta G, Touwaide A 2008. Continuity and change in the Mediterranean medical tradition: Ruta spp. (Rutaceae) in Hippocratic medicine and present practices. J Ethnopharmacol., 116:469-482.

Ramesh BN, Rao TSS, Prakasam A, Sambamurti K, Rao KSJ 2013. Neuronutrition and Alzheimer's disease. Journal of Alzheimer's Disease, 19:11231139.

Salvo G, Ho SYW, Rosenbaum G, Ree R, Conti E 2010. Tracing the temporal and spatial origins of island endemics in the Mediterranean region: a case study from the citrus family (Ruta L., Rutaceae). Systematic Biology, 59:705-722.

Shah MA, Don Bosco SJ, Mir SA 2014. Plant extracts as natural antioxidants in meat and meat products. Meat Science, 98, pp. 21-33.

Townsend CC 1967. Haplophyllum A.Juss. In: Davis, P.H (Ed.) Flora of Turkey and The Aegean Islands, vol 2. Edinburgh University Press, Edinburgh, pp 496-506.

Tugay O 2012. Rutaceae. Şu eserde: Güner, A., Aslan, S., Ekim, T., Vural, M., Babaç, M. T., (edlr.) Türkiye Bitkileri Listesi (Damarlı Bitkiler). NezahatGökyiğit Botanik Bahçesi ve Flora Araştırmaları Derneği Yayını. İstanbul.

Turgay O, Ulukuş D 2017. Haplophyllum sahinii(Rutaceae), a new species from Central Anatolia (Turkey).Phytotaxa, 29(3):265-272.

Ulubelen A, Ertugrul L, Birman H, Yigit R, Erseven G, Olgac V 1994. Antifertility effects of some coumarins isolated from Ruta chalepensis and R. chalepensis var. latifolia in rodents. Phytother Res., 8:233-236.

Zellagui A, Belkassam A, Belaidi A, Gherraf N 2012. Environmental impact on the Chemical Composition and yield of essential oils of Algerian Ruta Montana (Clus.) L and their antioxidant and antibacterial activities. Advances in Environmental Biology, 6 (10):2684-2688. 